\title{
O ESTADO, O MERCADO E AS USINAS HIDRELÉTRICAS NA REGIÃO OESTE CATARINENSE
}

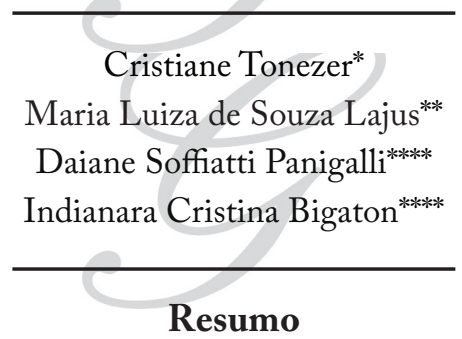

O uso de energia elétrica é essencial não só para o crescimento econômico, como também para a promoção do desenvolvimento. No Brasil, a matriz energética é formada, em sua maioria, pela energia elétrica proveniente de usinas hidrelétricas. Uma ampla quantidade desses empreendimentos é de grande porte, fato que favorece a ocorrência de graves danos ao meio ambiente e à população em seu entorno. Essas características justificam a importância deste estudo, pois pretende-se revisar a literatura com o intuito de compreender o atual panorama da região oeste de Santa Catarina no que tange aos projetos de geração de energia hidrelétrica. Para tanto, realiza-se uma revisão histórica desde o surgimento dos grandes projetos de barragens, sua evolução no trato com os impactos socais e ambientais, até a questão da privatização do setor. Além disso, é realizado um levantamento do atual panorama de geração de energia da região, bem como uma breve caracterização das principais usinas hidrelétricas existentes. Conclui-se que o atual modelo energético é resultado de um período político autoritário, que produziu projetos de forma centralizada e verticalizada. Conclui-se também que, apesar de inegáveis conquistas, no que tange aos aspetos sociais e ambientais, os danos ainda existem, e a lógica econômica, preponderante no período militar, ainda impera.

Palavras chave: Hidrelétricas. Bacia do rio Uruguai. Região oeste catarinense.

\footnotetext{
* Doutora em Desenvolvimento Rural pelo Programa de Pós-Graduação em Desenvolvimento Rural (PGDR) da Universidade Federal do Rio Grande do Sul (UFRGS). Docente do Programa de Pós-Graduação (Mestrado Profissional) em Políticas Sociais e Dinâmicas Regionais da Universidade Comunitária da Região de Chapecó (Unochapecó). E-mail: tonezer@unochapeco.edu.br.

** Doutora em Políticas e Processos Sociais pela Pontifícia Universidade Católica do Rio Grande do Sul (PUCRS). Atuou como docente do Programa de Pós-Graduação (Mestrado Profissional) em Políticas Sociais e Dinâmicas Regionais da Universidade Comunitária da Região de Chapecó (Unochapecó).

E-mail: mlajus@unochapeco.edu.br.

*** Graduada em Ciências Econômicas e Curso Superior Sequencial de Complementação de Estudos de Formação de Agentes para o Desenvolvimento Regional pela Universidade Comunitária da Região de Chapecó (Unochapecó). Atualmente, é economista da Universidade Federal da Fronteira Sul (UFFS) e mestranda do Programa de Pós-Graduação (Mestrado Profissional) em Políticas Sociais e Dinâmicas Regionais da Unochapecó. E-mail: daiane_soffiatti@yahoo.com.br.

**** Graduada em Comunicação Social - Jornalismo pela Universidade do Contestado (UNC), campus de Concórdia. Possui especialização em Desenvolvimento Regional pela Universidade Federal do Paraná (UFPR). Atualmente, é mestranda do Programa de Pós-Graduação (Mestrado Profissional) em Políticas Sociais e Dinâmicas Regionais da Universidade Comunitária da Região de Chapecó (Unochapecó).

E-mail: indianarac@unochapeco.edu.br.
} 


\section{Introdução}

No decorrer da história do Brasil, a política local passou por processos ora de centralização de poder, ora de descentralização. Esse pêndulo histórico deixa marcas nos processos de desenvolvimento do país, sendo que esse ocorre de forma desigual entre as regiões, ocasionando problemas socais latentes, e caracteriza-se por conflitos e jogos de interesses. Na década de 1950, criam-se os Grandes Projetos de Investimentos (GPI), que surgem como potencializadores para o crescimento econômico brasileiro. Em tempo retrógado, o processo desenvolvimentista tratou das grandes obras sem realmente planejar o desenvolvimento das regiões e ignorou as questões sociais e ambientais. Dentro desses grandes projetos, o Brasil, por ter grandes bacias hidrográficas e pelo advento dos avanços tecnológicos, utilizou-se da sua potencialidade natural hídrica para construções de hidrelétricas e posterior transmissão de energia para demais regiões do país.

Reconhece-se que as instalações de hidrelétricas foram importantes para desenvolver economicamente o país e contribuíram para o aumento do bem estar da sociedade. Porém, os custos desses grandes empreendimentos, até a década de 1980, não contemplavam a devastação ambiental e os impactos sociais causados aos ribeirinhos, aos indígenas, aos camponeses e às demais populações atingidas. Com o enfraquecimento do poder centralizador dos militares e do processo de redemocratização, foram criadas instituições ambientais e movimentos sociais a fim de garantir os diretos das populações atingidas e a preservação do meio ambiente.

Dentre as regiões atingidas por Grandes Projetos de Investimento (GPI) relacionados à hidroeletricidade, destacase a região oeste de Santa Catarina, uma vez que seu território geográfico é contemplado pela bacia do rio Uruguai, primeira bacia hidrográfica a possuir um inventário hídrico com utilização integral de pontos de aproveitamento.

Nesse cenário, o presente artigo tem por objetivo revisar a literatura quanto ao surgimento dos grandes projetos de 
barragens, sua evolução no trato com os impactos sociais e ambientais, até a questão da privatização do setor na região mencionada. Além disso, o artigo objetiva realizar um levantamento do atual panorama de geração de energia da região oeste catarinense.

Para tratar desses assuntos, este artigo será dividido em quatro partes: inicialmente, serão trazidos os Grandes Projetos de Investimentos e de que forma esses eram implementados, especificamente no que se refere às hidrelétricas; em um segundo momento, busca-se trazer informações referentes à bacia do rio Uruguai e ao processo de privatizações das hidrelétricas. Por fim, discorre-se sobre a atual posição da geração de energia hidrelétrica na região oeste catarinense, com uma breve exposição dos principais impactos socioeconômicos e ambientais causados pelos maiores projetos que atingiram municípios da região.

\section{Metodologia}

O presente artigo buscou descrever como foram projetados e implantados os grandes projetos de investimento ocorridos no Brasil, com ênfase nas hidroelétricas da bacia do Rio Uruguai, tratando da sua importância e dos impactos sociais gerados. Para tanto, utilizou-se como estratégia teórico-metodológica a pesquisa bibliográfica, isto é, o levantamento da literatura sobre o assunto a fim de conhecer como o tema foi tratado em outras experiências e como ocorre sua evolução conceitual combinada com a pesquisa documental.As principais bases bibliográficas consultadas quanto aos grandes projetos de investimento foram Araújo (1991), Haddad (1993) e Bortoleto (2001). Os estudos de Santos (2003), Scherer-Warren (2008) e Paim e Ortiz (2006) constituíram as principais referências no tocante à questão da hidroeletricidade na bacia do rio Uruguai.

O atual panorama da geração de hidroeletricidade na região oeste catarinense foi construído a partir de pesquisa documental realizada no Banco de Informações de Geração 
(BIG) da Agência Nacional de Energia Elétrica (ANEEL). O BIG disponibiliza informações quanto à capacidade instalada de geração de energia elétrica por unidade da Federação, discriminadas por tipo de empreendimento, potência, destino da energia, proprietário, município e rio. As informações relativas ao Estado de Santa Catarina foram sistematizadas para atender ao propósito do presente estudo.

\section{Grandes Projetos de Investimentos: as hidrelétricas}

$\mathrm{Na}$ década de 1950, o Brasil passou por um grande processo político de fomento à industrialização. Junto a isso, houve a necessidade de grandes investimentos em infraestrutura para garantir o crescimento econômico. Conforme descreve Bortoleto (2001,), os Grandes Projetos de Investimentos (GPI) comportavam empreendimentos de grande porte, que eram elaborados para expandir a industrialização e considerados como projetos de "desenvolvimento" nas regiões em que foram instalados. Como exemplo deles, pode-se citar: complexos de extração e de beneficiamento de recursos minerais e energéticos, refinarias de petróleo, centrais nucleares, grandes hidrelétricas, entre outros.

Os grandes projetos foram apresentados à sociedade como ações que contribuiriam para a diminuição das disparidades e das desigualdades regionais, contudo, as implantações dos projetos não passaram por um estudo aprofundado, no que tange aos locais em que deveriam ser desenvolvidos, bem como não foram consideradas as externalidades negativas atreladas à implantação dos mesmos, conforme Bortoleto (2001, p. 55):

Sendo elaborados em nome da industrialização brasileira e implantados com o discurso da interiorização do desenvolvimento econômico e de garantia da segurança nacional, os grandes projetos apresentavam um caráter fechado quanto às decisões de sua implantação, incentivos e subsídios estatais e ainda uma ausência de análises sobre as alterações socioeconômicas, culturais e ambientais que causariam às regiões. 
Araújo (1991) também faz apontamentos sobre os projetos de grande escala. Segundo o autor, grandes projetos de investimento solidificam o processo de apropriação de recursos naturais e humanos em determinadas regiões, uma vez que, possuindo lógica puramente econômica, submetem determinados territórios às decisões e definições conformadas em espaços relacionais exógenos aos das populações e locais do entorno dos empreendimentos. $\mathrm{O}$ autor ainda expressa que estes, quando infligidos e descolados das dinâmicas da região, trazem uma série de efeitos negativos, tais como a multiplicação das carências, a desestruturação do poder local e a segregação.

Para Haddad (1993), a promoção de grandes projetos de investimentos não garante à região onde se instalam condições estáveis de desenvolvimento. No caso brasileiro em específico, o autor assinala os "dramáticos custos diretos e indiretos em termos de danos ao meio ambiente e ao processo de desenvolvimento socioeconômico das áreas periféricas em que se inserem" (HADDAD, 1993, p. 265)

$\mathrm{Na}$ implantação dos grandes projetos de investimentos, a eletricidade gerada por grandes hidrelétricas estava em ascensão:

Abundância de recursos hídricos e facilidades de acesso a tecnologias de geração hidráulica já consolidadas nos países capitalistas centrais sinalizavam na direção da hidreletricidade como alternativa econômica mais eficiente no tocante aos investimentos produtivos do setor [...] (CENTRO DA MEMÓRIA DA ELETRICIDADE NO BRASIL, 1988 CARNEIRO, 2010, p. 98).

Nesse cenário, a Eletrobrás foi criada, em 1960, com o objetivo de regulamentar e tratar da expansão hidroelétrica no Brasil, respondendo pela gestão e pela aplicação dos recursos públicos no sistema. O posicionamento adotado foi o mesmo do governo vigente (militar), desconsiderando-se, portanto, os impactos que as hidrelétricas causariam e mantendo o discurso centralizador de que todos os projetos eram necessários e justificáveis para o desenvolvimento do Brasil. 
Para Cruz e Silva (2001, p. 57), acerca dos projetos de geração de energia hidrelétrica,

[...] as decisões que são tomadas referentes a este assunto dificilmente consideram as populações locais, uma vez que, defendem interesses nacionais e, às vezes, até internacionais. Utilizam-se do discurso do progresso e do desenvolvimento das regióes para justificar a construção de hidrelétricas e a retirada de pessoas.

Quanto aos efeitos danosos ao meio ambiente e ao processo de desenvolvimento das áreas em que os projetos foram implantados, Haddad (1993) argumenta que as razões para esses danos são várias e destaca três pontos principais: i) o período em que os projetos foram concebidos, quando a política era dominada pelo autoritarismo e impedia que as populações mais atingidas pelos danos sociais e ecológicos pudessem se manifestar e fazer proposições; ii) a etapa histórica em que os projetos foram desenvolvidos, na qual faltava uma consciência ecológica como força de contestação junto à opinião pública nacional; e iii) os custos sociais e ecológicos relacionados à implantação dos grandes projetos não eram incorporados na análise e na avaliação para fins de financiamento dos mesmos.

$\mathrm{Na}$ década de 1980, com o enfraquecimento dos militares e o início do processo de redemocratização, definiu-se a política nacional de meio ambiente e foram criados órgãos federais para colocar em prática os novos dispositivos legais, como o Conselho Nacional de Meio Ambiente (CONAMA), para a avaliação de impactos e o licenciamento de obras modificadoras do meio ambiente (entre elas, a elétrica), e documentos avaliadores como o Estudo de Impacto Ambiental (EIA) e o Relatório de Impacto Ambiental (RIMA). Todas as modificações para a implantação de projetos que causam danos ao meio ambiente surgiram também de reclamos da comunidade internacional em convenções anteriores à Conferência das Nações Unidas de Meio Ambiente e Desenvolvimento, realizada no Rio 
de Janeiro em 1992 (SANTOS, 2003). Além das questões ambientais, os problemas sociais também foram, aos poucos, sendo levantados e considerados, de forma que as noções de "área de influência", de "usos múltiplos", de "inserção regional" e de monitoramento foram incorporadas aos EIA e RIMA.

No final da década de 1980, já com a nova constituinte, o setor elétrico passou a ter uma nova reorientação organizacional. A Eletrobrás passou a ter dificuldades de crescimento, principalmente pela dificuldade de conseguir empréstimos no exterior e pelas disputas das empresas estaduais em ampliar as concessões de energia. Além disso, não se pode ignorar a reordenação econômica mundial que se dava no momento (SANTOS, 2003), isto é, o retorno da visão liberal, com a abertura de mercados, a diminuição do poder estatal a partir da cartilha imposta pelo Banco Mundial para a negociação das dívidas e para a liberação de novos financiamentos e o aumento do poder do mercado através da privatização das empresas estatais. Aliado a isso, a Constituição de 1988 vetou a continuidade da cobrança do Imposto Único sobre Energia Elétrica (IUEE), causando problemas financeiros insanáveis às estatais. Assim, em conjunto, o Banco de Desenvolvimento Econômico e Social (BNDES), parceiro da Eletrobrás, passou a orientar a favor das privatizações:

Nos anos [19]90, aceleraram-se as iniciativas de privatização do setor elétrico. A falta de investimentos para dar seguimento à implantação de diferentes hidrelétricas no país, previstas nos planos 2000,2010, 2020 e suas revisões, elaborados diligentemente pela Eletrobrás, associada à crescente demanda por energia, faziam prever uma crise de abastecimento sem precedentes. $O$ país estava numa situação de risco para dar continuidade aos seus planos de expansão econômica. Tornou-se inevitável, pois, a aceitação da modelagem do processo de privatização, que contemplava a atração de investimentos externos e estimulava a formação de consórcios nacionais, visando a implantação de novas hidrelétricas e, eventualmente, de termelétricas (SANTOS, 2003, p. 94) 
As cisões se tornaram frequentes, reordenando os setores de geração e de transmissão de energia. Segundo Abreu (1999), o setor elétrico brasileiro, nessa época, foi bastante cobiçado por empresas norte-americanas e suas parceiras (Quadro 1).

\section{Quadro 1 - Investimento estrangeiro em geração e distribuição de} eletricidade no Brasil

\begin{tabular}{|c|c|}
\hline ABB Energy Ventures (Suécia) & Participações em Termoelétrica \\
\hline AES (EUA) & $\begin{array}{l}\text { Possui participaçóes na Light }(11,3 \%)^{*} \text {, Cia. Centro-Oeste } \\
\text { de Distribução de Energia (RS) - ( } 100 \%)^{*} \text {, Eletropaulo } \\
\text { Metropolitana }(22,50 \%)^{*} \text {, participação na CEMIG }(14,42 \%)^{*} \text {, } \\
\text { tem participação na área de gás e em termoelétrica }\end{array}$ \\
\hline Comunity Alternative (EUA) ${ }^{* * *}$ & $\begin{array}{l}\text { Participação na Cia. Norte-Nordeste de Distribuição de } \\
\text { Energia (RS)- }(33,3 \%)^{*}\end{array}$ \\
\hline $\begin{array}{l}\text { CS\&W CO-Central and } \\
\text { Southwest System (EUA) }\end{array}$ & $\begin{array}{l}\text { Detém } 21 \% \text { do capital votante e } 36 \% \text { do capital social do Grupo } \\
\text { Rede que controla a EEB, Vale Paranapanema, Companhia } \\
\text { Nacional de Energia }\end{array}$ \\
\hline Electricity de France (França) & $\begin{array}{l}\text { Possui participação na Light }(22,50 \%)^{*} \text {, Eletropaulo } \\
\text { Metropolitana }(22,50 \%)\end{array}$ \\
\hline Edegel Peru (Peru) & $\begin{array}{l}\text { Possui participação nas Centrais Elétricas } \\
\text { Cachoeira Dourada }(20 \%)^{*}\end{array}$ \\
\hline Endesa (Espanha) & Possui participação na Cerj $(10 \%)^{*}$ e na Coelce \\
\hline Endesa (Chile) & $\begin{array}{l}\text { Possui participações nas Centrais Elétricas } \\
\text { Cachoera Dourada }(60 \%)^{*}\end{array}$ \\
\hline Enersis (Subsidiária da Endesa) & Possui participação na CERJ e em Cachoeira Dourada \\
\hline Enron(EUA) & $\begin{array}{l}\text { Possui participação na Elektro }(100 \%)^{*} \text {, Possui usinas } \\
\text { termoelétricas e participa na área do gás }\end{array}$ \\
\hline EDP (Portugal) & $\begin{array}{l}\text { Possui participação na Cerj }(30 \%)^{*} \text {, Coelce }(30 \%)^{*} \mathrm{e} \\
\text { na Bandeirantes }(56 \%)^{*}\end{array}$ \\
\hline Houston Industries Inc (EUA) & $\begin{array}{l}\text { Possui participação na Light }(11,3 \%)^{*} \text { e na } \\
\text { Metropolitana }(22,50 \%)^{*} \text {. }\end{array}$ \\
\hline Iberdrola(Espanha) & Possui participação na Coelba $(39 \%)^{*}$ e na Cosern $(12,2 \%)^{*}$ \\
\hline Southern Company (EUA) & Possui participação na Cemig \\
\hline Tractebell_(Bélgica) & Possui narticinacão na_Gerasul $(100 \%) *$ \\
\hline
\end{tabular}

Fonte: Abreu (1999, p. 13).

* Refere-se à porcentagem do lote total que foi a leilão.

** Esta empresa pertence à Plublic Service Eletric and Gas Global - Pseg Global (EUA).

Nota-se, a partir do Quadro 1, que a grande maioria das empresas estrangeiras apresenta participação em mais de um empreendimento, evidenciando o quão atrativo se configurava o mercado brasileiro de geração de eletricidade.

Nesse processo de cisões e de privatizações, a Eletrosul, subsidiária da Eletrobrás, passou por divisão, dando origem às Centrais Geradoras do Sul do Brasil S/A (Gerasul), posteriormente privatizadas e adquiridas pelo grupo belga Tractebel, Electricity \& Gas International, e à Empresa 
Transmissora de Energia Elétrica do Sul do Brasil S/A (Eletrosul). Nessa nova configuração, o governo passou a ter atribuição de controle sobre essas empresas a partir da criação destas instituições: a Agência Nacional de Energia Elétrica (ANEEL), o Operador Nacional do Sistema (ONS) e a Câmara de Gestão da Crise de Energia (GCE).

Com esse novo cenário, a bacia do rio Uruguai, para a qual já havia um projeto para a implantação de hidrelétricas, teve várias alterações, em consonância com a nova realidade imposta.

\section{A bacia do rio Uruguai}

A bacia do rio Uruguai (Figura 1) está localizada nos Estados de Santa Catarina e do Rio Grande do Sul. De acordo com Carneiro (2000), na década de 1960, os primeiros estudos para aproveitamento elétrico da bacia foram realizados pelo Consórcio Canadense-Americano-Brasileiro (Canambra). $\mathrm{Na}$ década de 1970, com a criação da Eletrosul, subsidiária da Eletrobrás, foram retomados os estudos, elaborandose o inventário hídrico da bacia do rio Uruguai. O projeto foi o primeiro a prever a utilização integral de uma bacia hidrográfica, com cerca de 22 pontos assinalados como passiveis de aproveitamento.

O projeto ganhou força a partir dos avanços tecnológicos relativos às linhas de transmissão de energia a longa distância, o que abriu novas perspectivas de aproveitamento hídrico em regiões mais remotas. A proposta de aproveitamento integral da bacia hidrográfica levou em consideração diversas variáveis, como a minimização das questões sócio-ambientais. Contudo, de acordo com Santos (2003), a tônica do projeto continuava baseada no planejamento centralizado e verticalizado.

A divulgação do projeto, no final dos anos 1970, coincidiu com o enfraquecimento do regime militar, o que facilitou a reação, nas áreas rural e urbana, das populações potencialmente atingidas. Nesse período, surgiram os movimentos sociais, como a Comissão Regional dos 
Atingidos por Barragens (CRAB), que tinha como objetivo a resistência aos projetos e a suas formas de implantação, que desconsideravam as realidades locais. Segundo SchererWarren (2008), a Eletrosul precisou enfrentar uma forte reação das populações locais, constituída sobretudo por agricultores. Por isso, veio a público o inventário hidroenergético da Bacia do Uruguai em novembro de 1979.

\section{Figura 1 - Bacia do Rio Uruguai}

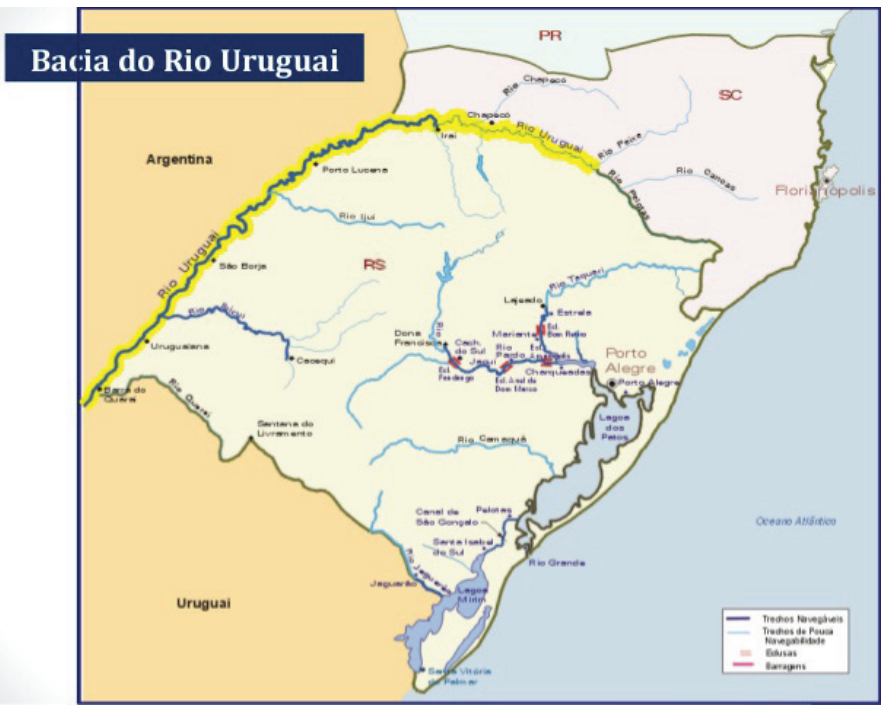

Fonte: ANA,[2016]

A CRAB, por meio de sua mobilização e articulação, conforme Scherer-Warren (2008), obteve grandes conquistas na implantação das usinas da bacia do rio Uruguai, principalmente no que tange aos projetos de reassentamento, ao apoio logístico à população atingida e às compensações financeiras. Entre seus maiores êxitos, cabe destacar a alteração do projeto da Usina Hidrelétrica (UHE) de Machadinho, no Rio Grande do Sul, o qual inicialmente previa a inundação de boa parte de terras indígenas e camponesas. Na década de 1990, a Eletrosul retomou do projeto da construção da usina e deu andamento à formação de um consórcio privado para a viabilização do investimento. 
Este foi o primeiro consórcio para a implantação de uma UHE na bacia do Uruguai. Rapidamente, outros foram organizados para a construção das UHE de Campos Novos (374 MW), Barra Grande (609 MW), Quebra-Queixo (162 MW), Foz do Chapecó (184 MW) e Pai Querê (288 MW). Os demais aproveitamentos têm perspectivas de serem também colocados à disposição de novos consórcios privados, a curto prazo (SANTOS, 2003, p. 97).

A Eletrosul também retomou o projeto da UHE de Itá, em Santa Catarina, afetando uma área de $141 \mathrm{~km}^{2}$ - incluindo a parte inundada e as áreas de preservação ambiental - e atingido aproximadamente 3.500 famílias. A cidade de Itá ficou totalmente alagada, sendo necessária sua reconstrução.

A construção do empreendimento era, inicialmente, de responsabilidade da Eletrosul, sendo que a partir de 1995, se firmou uma parceria com a iniciativa privada, quando a Gerasul (parte da Eletrosul detentora do parque gerador da Empresa) e a Companhia Siderúrgica Nacional (CSN), a Companhia de Cimento Itaimbé e a Odebrecht Química S.A. formaram o Consórcio Itá e passaram a gerenciar o empreendimento. Com a privatização da Gerasul, o empreendimento passa a ser controlado totalmente pela iniciativa privada (KÖLLN; SILVA, 2010, p. 5-6).

Nesse sentido, Santos (2003) considera que a implantação de projetos hidrelétricos implica na existência de múltiplos atores sociais e de diferentes interesses políticos, econômicos e empresariais. Não se trata só de desafios de engenharia, nem tampouco do domínio de novas tecnologias: cada implantação de hidrelétricas, no Brasil, teve sua especificidade, mas, em comum, provocaram impactos ambientais e sociais, principalmente aos ribeirinhos. Com as privatizações, ficou evidente um retrocesso no processo de redemocratização.

A realidade do processo de privatização do setor elétrico no cenário neoliberal aparece, assim, por inteiro. As noções de "direito difuso", de "efeito global" 
e de "externalidade" [...] não estão sendo consideradas tanto pelos burocratas do setor elétrico quanto pelos novos parceiros privados (SANTOS, 2003, p. 101).

Nesse cenário, cabe ao Governo Federal e a seus órgãos reguladores a segurança na implantação desses investimentos, para garantir o menor impacto ambiental possível e o reconhecimento, em sua totalidade, dos atingidos. Obras dessa envergadura implicam toda uma logística local, nacional e global, pois as suas consequências não se limitam a um único espaço.

\section{Oeste catarinense: a geração de hidroeletricidade}

A região oeste de Santa Catarina, pertencente à bacia do rio Uruguai, concentra boa parte dos empreendimentos de geração de energia hidrelétrica presentes no estado, conforme pode ser observado no Gráfico 1. Atualmente, dos 206 empreendimentos de geração de energia hidrelétrica presentes em Santa Catarina, 89 estão localizados na Região Oeste, sendo eles 53 Centrais Geradoras Hidrelétricas (CGH), 33 Pequenas Centrais Hidrelétricas ( $\mathrm{PCH})$ e três Usinas Hidrelétricas (UHE).

Segundo informações extraídas junto à ANNEL (2016), os empreendimentos presentes na região constituem mais de 49,0\% da potência instalada no estado catarinense.

Os números apresentados, mesmo que expressivos, ainda não demostram o quanto a região é afetada por esse tipo de empreendimento, uma vez que a localidade considerada pela ANEEL é aquela em que reside a casa de máquinas da geradora de hidroeletricidade, não englobando, portanto, duas grandes obras existentes na bacia do rio Uruguai: UHE Itá e UHE Foz do Chapecó.

Quanto à destinação da energia produzida pelas 33 Pequenas Centrais Hidrelétricas ( $\mathrm{PCH}$ s) e pelas três Usinas Hidrelétricas (UHEs) presentes na região oeste, apenas cinco das centrais geradoras destinam a energia para a modalidade Autoprodutor de Energia Elétrica (PIE), que consiste na 
concessão ou autorização para produzir energia destinada exclusivamente à pessoa física ou jurídica ou ao consórcio que recebeu a autorização. Outras 29 centrais destinam a energia produzida à modalidade Produtor Independente de Energia Elétrica (PIE), que consiste na concessão ou autorização para pessoa jurídica ou consórcio de poder produzir energia elétrica destinada ao comércio de toda ou parte da energia produzida, por sua conta e risco. Quanto às outras duas centrais de geração de energia hidrelétrica, uma atua nas modalidades APE e Serviço Público (SP) e a outra, nas modalidades PIE e SP. Cabe informar que a CELESC é proprietária de somente uma PCH, localizada no município de Faxinal dos Guedes. Os demais empreendimentos pertencem a consórcios privados ou a pessoas jurídicas.

\section{Gráfico 1 - Empreendimentos de geração de energia hidrelétrica em operação}

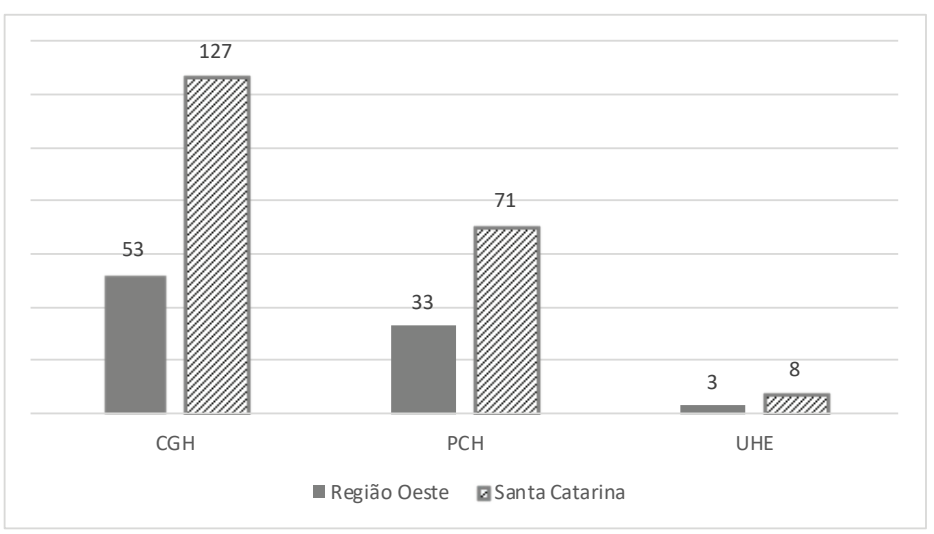

Fonte: Elaborado pelos autores a partir de dados da ANEEL (2016).

Legenda: CGH - Central Geradora Hidrelétrica / PCH - Pequena Central Hidrelétrica / UHE - Usina Hidrelétrica.

Dentre as obras de barragens que atingiram a região, merecem destaque, por sua magnitude - tanto no que diz respeito à potência energética quanto aos danos sociais e ambientais causados -, a UHE Machadinho, a UHE Itá e a UHE Foz do Chapecó. Segue uma breve descrição dos projetos: 
$\underline{\text { UHE Machadinho }}$

Em operação desde 2001, a usina hidrelétrica está localizada no rio Pelotas, entre os municípios de Piratuba (SC) e Maximiliano de Almeida (RS). A usina possui potência de $1.060 \mathrm{MW}$ e seu reservatório atinge a área de $56,7 \mathrm{~km}^{2}$. O empreendimento está concedido a um consórcio formado por: Tractebel Energia; Cia. Brasileira de Alumínio; DME; CELESC; CEEE; Camargo Corrêa Cimentos S/A; Valesul Alumínios S/A; Alcoa Alumínios S/A; Cimento Rio Branco S/A; e Inepar Energia S/A. Quantos aos principais impactos, segundo Paim e Ortiz (2006), foram atingidas 1.850 famílias, totalizando cerca de oito mil pessoas, das quais cerca de duas mil eram sem terras. Os atingidos são dos seguintes municípios: Maximiliano de Almeida, Machadinho, Barracão e Esmeralda, no Estado do Rio Grande do Sul, e Piratuba, Capinzal, Zórtea, Campos Novos, Celso Ramos e Anita Garibaldi, no Estado de Santa Catarina. A energia é destinada ao PIE e ao SP.

\section{UHE Itá}

Em operação desde 2000, a usina possui potência de 1.315 MW. Ela está localizada no rio Uruguai, entre os Municípios de Itá (SC) e Aratiba (RS), e seu reservatório abrange a área de $141 \mathrm{~km}^{2}$. O empreendimento de mais de $\mathrm{R} \$ 1$ bilhão recebeu apoio do BNDES no valor de $\mathrm{R} \$ 542$ milhões. O consórcio que detém a concessão do projeto é formado por Tractebel e Itá Energética. Com relação aos impactos, de acordo com Paim e Ortiz (2006), foram inundados 10.260 hectares com potencial agrícola e cerca de 3.500 famílias foram diretamente atingidas. No Estado do Rio Grande do Sul, foram atingidos os seguintes municípios: Aratiba, Mariano Moro, Severiano de Almeida, e Marcelino Ramos; no Estado de Santa Catarina, os municípios atingidos foram Itá, Concórdia, Alto Bela Vista, Piratuba, Ipira e Piritiba. O município de Itá foi a primeira cidade brasileira a ser totalmente coberta pelas águas de uma barragem; na ocasião, foram atingidas 3.219 propriedades, 3.585 famílias e 
36 comunidades rurais. A cidade de foi totalmente realocada em 1997. A energia produzida é destinada ao PIE.

\section{UHE Foz do Chapecó}

Em operação desde 2010, com potência de 855 MW e área de reservatório de $70 \mathrm{~km}^{2}$, a usina está localizada no rio Uruguai, entre Alpestre (RS) e Águas de Chapecó (SC). $\mathrm{O}$ projeto, com custo total de mais de $\mathrm{R} \$ 2,6$ bilhões, teve $70 \%$ do valor financiado pelo BNDES e por um consórcio de bancos privados. O Consórcio Foz do Chapecó, detentor da concessão, é formado por Furnas Centrais Elétricas, Foz do Chapecó Energia e CEEE. Os municípios atingidos pelo projeto são: Alpestre, Rio dos Índios, Itatiba do Sul, Nonoai, Erval Grande, Faxinalzinho e Barra do Rio Azul, no Estado do Rio Grande do Sul, e, no Estado de Santa Catarina, Águas de Chapecó, Guatambu, Chapecó, Caxambu do Sul, Paial e Itá. De acordo com Paim e Ortiz (2006), há sítios arqueológicos indígenas na região. As propriedades atingidas pelo empreendimento, de acordo com a Foz do Chapecó Energia (2016), foram 1.700, e cerca de duas mil indenizações concedidas. A energia produzida é destinada ao PIE.

\section{Considerações finais}

Os grandes projetos de investimento foram concebidos em uma época de autoritarismo político, e, no que se refere às hidrelétricas, não seguiram o critério de preservação do meio ambiente e de segurança dos direitos dos atingidos pelas barragens. Os impactos sociais somente passaram a ser considerados - e os direitos dos atingidos assegurados - com a redemocratização no Brasil, a partir dos anos 1980, com a nova constituinte (1988) e com as ações do movimento social constituído, a Comissão Regional de Atingidos por Barragens (CRAB). Cabe ressaltar que as políticas para proteção ambiental só foram tomadas devido à forte pressão internacional, de forma que o Brasil viu-se obrigado a adotá-las. 
A era desenvolvimentista também não trouxe, necessariamente, desenvolvimento às regiões onde foram instaladas as hidroelétricas, visto que os projetos foram implantados de forma centralizada e verticalizada, ignorando as configurações regionais. Aliado a isso, o processo global de privatizações afetou diretamente as empresas estatais de energia, que, sem solução, abriram espaço para consórcios privados, em sua maioria com participação de empresas estrangeiras. Tal processo, forçado após a Constituição de 1988, criou obstáculos ainda maiores aos atingidos, no que tange à negociação de suas indenizações.

Nesse contexto, a região oeste de Santa Catarina, área de grande potencial de geração de energia hidrelétrica e que abarca grande parte dos empreendimentos do gênero no estado, vem sofrendo severos danos ambientais e sociais. As três maiores barragens (UHE Itá, UHE Machadinho e UHE Foz do Chapecó) afetaram mais de 7.350 famílias, entre elas populações camponesas, ribeirinhas e indígenas de Santa Catarina e do Rio Grande do Sul. Juntos, esses empreendimentos inundaram uma área de aproximadamente $267 \mathrm{~km}^{2}$, encobrindo flora, fauna, terras com potencial agrícola e até uma cidade, como foi o caso de Itá (SC), que ficou totalmente submersa.

Compreende-se, entretanto, a importância das obras hidrelétricas para fomentar o crescimento econômico brasileiro e o fato de a eletricidade ser uma das necessidades básicas dos seres humanos. A crítica fica a cargo dos danos ambientais e sociais provocados, muitas vezes não contabilizados no custo do projeto. Além disso, cabe crítica ao atual modelo de concessão de exploração de energia hidrelétrica, que garante alta rentabilidade aos consórcios e empresas privadas, a qual raramente é revertida em forma de investimentos nas regiões afetadas pelas hidrelétricas.

\section{Referências}
ABREU, Yolanda Vieira de. A Reestruturação do setor elétrico brasileiro: questões e perspectivas. Dissertação (Pós-graduação em Energia) - Universidade de São Paulo, São Paulo, 1999 
ARAUJO, Frederico G. B. Modernização e conflito no Brasil contemporâneo. In: ENCONTRO NACIONAL DA ANPUR, 4., 1991, Salvador. Velhas e Novas Legitimidades na Reestruturação do Território - Salvador. Salvador: ANPUR, 1991. p. 221-227

AGÊNCIA NACIONAL DE ÁGUAS - ANA. Agência Nacional de Águas. Brasília, [2016]. Disponível em: <www.ana.gov.br>. Acesso em: 18 ago. 2016.

AGÊNCIA NACIONAL DE ENERGIA ELÉTRICA ANEEL. Banco de informações. Brasília: ANEEL, 2016.

BORTOLETO, Elaine Mundim. A implantação de grandes hidrelétricas: desenvolvimento, discurso, impactos. Geografares, São Paulo, n. 2, p. 53-62, jun. 2001.

CARNEIRO, Ricardo. Estado, mercado e o desenvolvimento do setor elétrico brasileiro. 2000. 400 f. Tese (Doutorado em Ciências Humanas)-Faculdade de Filosofia e Ciências Humanas, Universidade Federal de Minas Gerais, Belo Horizonte, 2000.

CRUZ, Carla Buiatti; SILVA, Vicente de Paulo da. Grandes projetos de investimento: a construção de hidrelétricas e a criação de novos territórios. Soc. nat. (Online), , v. 22, n. 1, p.181-190, abr. 2010.

FOZ DO CHAPECÓ ENERGIA S.A. Foz do Chapecó Energia S.A. [Florianópolis], 2016. Disponível em: < http://www. fozdochapeco.com.br/>. Acesso em: 27 jan. 2016.

HADDAD, Paulo R. Região, regionalismo e desequilíbrios espaciais de desenvolvimento: algumas reflexões. Indicadores Econômicos FEE, Porto Alegre, v. 21, n. 2, p. 255-270, 1993.

KÖLLN, A. D. ; SILVA, M. Grupos de Poder e a Implantação da Usina Hidrelétrica de Itá-SC. In: ENCONTRO NACIONAL DE GEÓGRAFOS, 16., 2010, Porto Alegre. XVI Encontro nacional de Geógrafos: Crise, Práxis e Autonomia: Espaços de resistência e de Esperanças. Porto Alegre: UFRGS, 2010.

PAIM, Elisangela S.; ORTIZ, Lúcia S. Hidrelétricas na bacia do rio Uruguai: guia para ONGs e movimentos sociais. Porto Alegre: Núcleo Amigos da Terra/Brasil, 2006.

SANTOS, S. C. A Geração hídrica de eletricidade no sul do Brasil e seus impactos sociais. Etnográfica, Lisboa, v. 7, n. 1, p. 87-102, 2003.

SCHERER-WARREN, Ilse. Do local ao global: a trajetória do movimento dos atingidos por barragens (MAB) e sua articulação 
em redes. In: Franklin Daniel Rothman. (Org.). Vidas alagadas:

conflitos socioambientais, licenciamento e barragens. Viçosa: UFV, 2008. p. 66-84.

Submetido em: 23/05/2016

Aprovado em: 14/12/2016

\title{
STATE, MARKET AND HYDROELETRIC POWER PLANTS INTHE WEST REGION OF SANTA CATARINA STATE
}

\begin{abstract}
The use of electricity is essential for economic growth, as well to promote development. In Brazil, the energy matrix is formed mostly from hydroelectric plants. Most of these enterprises is large, a fact that favors the occurrence of serious damage to the environment and the population to its surroundings. These characteristics justify the importance of this study. In this sense, the present study aims to review the literature to understand the current situation in the region with regard to projects of hydropower generation. To this end, a historical review since the emergence of large dams projects, their progress in dealing with social and environmental impacts, until the privatization of the sector. In addition, it conducted a survey of the current situation of power generation in the Western region of Santa Catarina, as well as a brief description of the main existing hydroelectric plants in the region. We conclude that the current energy model is the result of an authoritarian political period that produced projects in a centralized and vertical structure. It is also concluded that despite undeniable achievements in relation to social and environmental aspects, the damages still exist and the economic logic still reigns.
\end{abstract}

Keywords: Hydroeletrics. Basin of the Uruguay River. Western Region of Santa Catarina. 